\title{
Condições e processo de trabalho no cotidiano do Programa Saúde da Família: coerência com princípios da humanização em saúde
}

\author{
Conditions and work process in the daily of the Family Health \\ Program: coherency with health humanization principles
}

Leny Alves Bomfim Trad ${ }^{1}$

Ana Angélica Ribeiro de Meneses e Rocha ${ }^{1}$

${ }^{1}$ Programa Integrado de Pesquisa e Cooperação Técnica em Comunidade, Família e Saúde (Fasa), Instituto de Saúde Coletiva da Universidade Federal da Bahia. Rua Basílio da Gama $\mathrm{s} / \mathrm{n}^{\circ}$, Campus

Universitário Canela. 40110-040 Salvador BA. trad@ufba.br

\begin{abstract}
This study analyzes humanization at work in the context of the Family Health Program (FHP), inquiring: what is the role that infrastructure assumes in the construction of humanized work in the FHP? Does the course of staff work reveal coherency with health humanization principles? In order to find out answers to these questions, it was explored the perception of FHP' professionals about their work routine, considering concrete conditions whereby it occurs besides involved relationships, practices and products. It is a multiple case study, both qualitative and quantitative (with primacy of the first approach), developed through questionnaires and focal-groups with FHP' teams of selected areas. The results indicate that infrastructure fragilities and low investment in training of staffs are factors that contribute for the persistence of work conditions and practices that are far away from health humanization principles. Despite of the difficulties, it was evidenced, by the staffs, in general way, great engagement to their work and great sensibility to population needs and problems.
\end{abstract}

Key words Humanization, Family Health Program, Works conditions, Work process
Resumo Este estudo analisa a humanização no trabalho no contexto do Programa Saúde da Família, indagando: que papel desempenha a infraestrutura para a construção de um trabalho humanizado no PSF? O processo de trabalho das equipes revela coerência com os princípios da humanização em saúde? Para buscar respostas para estas perguntas foi explorada a percepção de profissionais do PSF sobre o cotidiano do seu trabalho, considerando as condições concretas em que ele se realiza e as relações, práticas e produtos gerados neste processo. Trata-se de um estudo de casos múltiplos de tipo quali-quanti, com primazia do enfoque qualitativo, realizado através de questionários e grupos focais com equipes do PSF em áreas selecionadas. Os resultados indicam que as fragilidades de infraestrutura e o investimento tímido em formação das equipes são fatores que contribuem para a persistência de condições e práticas de trabalho que se distanciam dos princípios da humanização em saúde. Apesar das dificuldades apontadas, as equipes estudadas revelaram, de modo geral, um alto grau de comprometimento com o trabalho que desenvolvem e alta sensibilidade diante das necessidades e problemas da população.

Palavras-chave Humanização, Programa Saúde da Família, Condições de trabalho, Processo de trabalho 


\section{Introdução}

Entre as diretrizes da Política Nacional de $\mathrm{Hu}$ manização (PNH) em saúde, encontramos referência à valorização dos diferentes sujeitos implicados no processo de produção de saúde e o fomento à sua autonomia e protagonismo. Dentre esses sujeitos, destacamos os trabalhadores de saúde, os quais estão diretamente associados com outras duas diretrizes da PNH: a mudança nos modelos de atenção e gestão dos processos de trabalho - tendo como foco as necessidades dos cidadãos e a produção de saúde - e o compromisso com a ambiência, melhoria das condições de trabalho e de atendimento ${ }^{1}$.

O espaço de atuação do Programa Saúde da Família (PSF) revela-se um lócus privilegiado para analisar os desafios no que se refere à operacionalização das diretrizes referidas. A atuação cotidiana nas demandas de saúde mais frequentes, que incluem uma multiplicidade de questões sociais traduzidas como de saúde (e que aí se estabelecem pela ausência de outros espaços sociais de expressão ${ }^{2}$ ), demanda uma ação multiprofissional e articulação intersetorial ${ }^{3}$.

Com efeito, as equipes do PSF necessitam de novas formas de organização do trabalho e de tecnologias de produção. Entre "problemas da vida" e "patologia", as respostas exigidas não dependem apenas do arsenal diagnóstico-terapêutico da biomedicina; são requeridas novas tecnologias de escuta e de negociação, assim como outras regras comportamentais e organizacionais ${ }^{3}$.

Ao problematizar a questão da humanização em saúde a partir da perspectiva do trabalho e do trabalhador no contexto do PSF, assume-se o pressuposto de que o cotidiano do trabalho é um foco privilegiado para se avaliar a articulação entre qualidade do trabalho, saúde no trabalho e humanização do cuidado ${ }^{3}$, dialogando com noções como motivação, satisfação, saúde e segurança no trabalho. Utilizando o conceito de Qualidade (de Vida) n(d)o Trabalho (QVT), Lacaz e Sato ${ }^{4}$ identificam três elementos principais que comprometem a qualidade do trabalho e/ou a saúde dos trabalhadores: as condições de trabalho (jornadas, sobrecarga), a impossibilidade de atender adequadamente as demandas que se apresentam no trabalho e as exigências impostas ao trabalhador na contemporaneidade. Os autores chamam a atenção para o fato de que o trabalho moderno incorpora exigências contraditórias que repercutem na saúde dos trabalhadores, tais como maior intensidade de ritmo; maior controle e conhecimento do trabalho; polivalência; criatividade; maior liberdade de ação e critérios claros de avaliação, o que também vem sendo incorporado aos serviços de saúde. Advertem ainda para o fato de que a exigência de um trabalhador participativo e polivalente é vivenciada de forma ambígua, ou seja, como "aumento" de responsabilidade, "maior" carga de trabalho e "menor" autonomia. Devem-se acrescentar aqui as tensões advindas da ditadura institucional da produtividade, do isolamento das atividades profissionais e das exigências das transformações tecnológicas ${ }^{5}$.

A fragmentação do trabalho e os apelos da tecnocracia conduzem as práticas na direção contrária à valorização dos sujeitos e das relações entre eles. Torna-se imperativa a transformação dos modos de construção das políticas públicas de saúde, favorecendo o reposicionamento dos sujeitos e as esperadas mudanças na assistência ${ }^{6}$. As relações de poder que se instauram entre as diferentes categorias profissionais (reproduzindo em muitos casos as diferenças de classes ou de poder corporativo) é outro elemento conflitante na dinâmica das equipes mesmo em modelos como o do PSF, centrados no multiprofissionalismo e na interdisciplinaridade ${ }^{7,8}$.

A categoria “organização do trabalho" ocupa um papel central na tarefa de articular qualidade na atenção, saúde no trabalho e humanização do cuidado $^{4}$ - seja na visão taylorista (que concebe a existência de um melhor jeito de fazer o trabalho) ou na visão sociotécnica, que localiza em qualquer organização a existência simultânea de duas dimensões: a social (valores, regras, expectativas, características psicológicas) e a técnica (procedimentos, tarefas, equipamentos). Em sintonia com esta visão, Benevides e Passos ${ }^{6,9}$ advertem para o fato de que a mudança no atendimento à população nos serviços de saúde passa necessariamente pela alteração da organização dos processos de trabalho, da dinâmica de interação das equipes, dos mecanismos de planejamento, de decisão, de avaliação e de participação. Cabe interrogar ainda se os profissionais de saúde exercem algum mecanismo de autogoverno durante a realização do seu trabalho de modo a transformar os modos de produção ${ }^{10}$.

Convém ressaltar que, aliada às transformações de caráter organizacional ou político, a humanização do trabalho em saúde implica a ressignificação do saber e da prática em saúde, ou, em um sentido mais amplo, do seu objeto. Com relação ao apelo da cultura tecnológica em saúde, o momento assistencial pode e deve fugir de uma objetivação "dessubjetivadora”, da interação tão obcecada pelo "objeto de intervenção" que deixa de perceber e aproveitar as trocas mais amplas 
que ali se realizam ${ }^{9}$. Embora a interação terapêutica se apoie na tecnologia, não se limita a ela, devendo se articular com um cuidar para além da aplicação mecânica das tecnologias disponíveis, ao examinar a relação entre finalidades e meios, e seu sentido prático para o paciente. Ayres ${ }^{11}$ salienta que o cuidado em saúde mobiliza um saber que se distingue do técnico-científico e do trabalho artesanal, como livre exercício de subjetividade criadora. Ele aponta a práxis ou atividade prática como espaço privilegiado do cuidado, o qual amalgama os sujeitos nas interações terapêuticas.

A partir do referencial apresentado, o presente estudo analisa a humanização no trabalho no contexto do Programa Saúde da Família, indagando: qual a importância da infraestrutura de serviços para a construção de um trabalho humanizado no PSF? O processo de trabalho das equipes revela sintonia com os pressupostos da humanização? Para buscar respostas para estas perguntas, foi explorada a percepção de profissionais do PSF sobre o cotidiano do seu trabalho, considerando as condições concretas em que ele se realiza e as relações, práticas e produtos gerados neste processo.

\section{Metodologia}

Este trabalho integra uma pesquisa mais ampla sobre humanização no PSF realizado em três estados do Nordeste: Bahia, Sergipe e Ceará. Trata-se de um estudo de casos múltiplos ${ }^{12,13}$ de tipo quali-quanti, com primazia do enfoque qualitativo. O estudo contemplou um total de seis municípios, sendo dois de cada estado, selecionados com base nos seguintes critérios: um município de pequeno porte com até 20.000 habitantes e um município de grande porte com mais de 100.000 habitantes, excluindo-se as capitais. Com base nestes critérios, foram selecionados os seguintes municípios: Vitória da Conquista e Madre de Deus, na Bahia; Nossa Senhora do Socorro e Carmópolis, em Sergipe; Maracanaú e Pindoretama, no Ceará.

$\mathrm{Na}$ definição das áreas de estudo, foram escolhidas quatro unidades de saúde nos municípios de maior porte (em área com boa qualidade de vida, área com qualidade de vida intermediária, área bastante precária e área rural, semirrural ou bastante periférica) e duas unidades de saúde nos municípios de pequeno porte (área urbana e área rural ou semirrural).

Para atender aos objetivos estabelecidos, combinou-se uma abordagem extensiva de caráter mais quantitativo, com estratégias qualita- tivas referidas a um universo mais restrito. Foi desenvolvido um questionário aplicado a uma amostra significativa de equipes do PSF existentes nos municípios selecionados e outro dirigido a uma amostra de usuários atendidos pelas mesmas equipes. Paralelamente, foram realizados grupos focais (GF) com as equipes e os usuários, possibilitando uma abordagem em profundidade das questões estudadas. No escopo deste artigo, se focaliza o eixo das condições e processo de trabalho das equipes. Serão destacados, portanto, os resultados gerados através dos questionários e grupos focais dirigidos às equipes do PSF.

Foram aplicados 168 questionários entre as equipes das unidades selecionadas, os quais foram analisados através do programa Epi Info. Realizaram-se 18 grupos focais, envolvendo um total de 164 profissionais. O número de participantes nos grupos variou entre 8 e 14 (média de 11 profissionais por grupo), e o tempo médio de duração foi de uma hora e vinte minutos. Não foi registrada nenhuma recusa em participar da pesquisa. Eventualmente, foram reprogramados grupos focais ou atividades de aplicação de questionários de modo a se compatibilizarem com a agenda das equipes de saúde.

A distribuição pela categoria profissional entre os respondentes dos questionários foi similar à composição registrada nos grupos focais. A representação foi de $32 \%$ de profissionais de nível superior (médico, enfermeira, dentista etc.), $18 \%$ de auxiliares de enfermagem e 50\% de agentes comunitários de saúde (ACS) (53\%). Vale notar que $85 \%$ dos participantes do estudo eram do sexo feminino. Nos seis municípios pesquisados, a maioria dos profissionais tinha de dois a cinco anos no programa (12,5\% entre um e dois anos, $40,7 \%$ entre dois e cinco anos) e $30,4 \%$, mais de cinco anos. Registraram-se como exceções no perfil descrito a situação de uma farmacêutica e a de um fisioterapeuta, incorporados há menos de seis meses no programa em dois dos municípios estudados.

O produto das gravações dos grupos foi transcrito e analisado seguindo três etapas: de préanálise (exploração do material ou descrição analítica), de tratamento dos resultados e a fase de interpretação ${ }^{14}$. Na produção e na análise dos dados, foram consideradas duas categorias principais: "qualidade de infraestrutura/condições de trabalho e processo de trabalho da equipe". A pesquisa seguiu rigorosamente as recomendações éticas previstas na Resolução no 196/96 do Conselho Nacional de Saúde, relativa à pesquisa envolvendo seres humanos. Todos os entrevistados assinaram o Termo de Consentimento Livre e 
Esclarecido, e o projeto teve a anuência dos gestores municipais dos seis municípios.

\section{Resultados e discussão}

\section{Qualidade de infraestrutura/condições de trabalho}

A precariedade das instalações das unidades de saúde da família (USFs) aparece como um conteúdo recorrente em diferentes relatos. São depoimentos que apontam problemas de inadequação e manutenção das unidades de saúde da família ou da infraestrutura do sistema local de saúde. São destacadas a ausência de espaços físicos apropriados nas unidades (problemas com tamanho e/ou disposição das salas, climatização, ruído etc.), fato que repercute negativamente na realização de atividades consideradas essenciais para o programa ${ }^{15,16}$.

Até a sala de espera não é arejada, é quente, o usuário fica insatisfeito, fica impaciente, então não tem assim... não tem uma estrutura física adequada pra isso. (Dentista, Maracanaú, CE)

Aqui não tem sala para reunião nem trabalho de grupo. A gente utiliza a igreja para fazer estas atividades. (Enfermeira, Vitória da Conquista, BA)

Devia fazer a manutenção do prédio, pois mesmo que o atendimento seja bom, o ambiente gera má impressão. (Médica, Vitória da Conquista, BA)

$O$ auditório não tem cadeiras. A sala de espera não tem lugar suficiente pra todo mundo e é quente, o bebedouro não funciona direito, as salas cheias de infiltrações... Aqui é uma sala de exame de lâmina, está dessa forma. [...] fazer uma palestra com grupos não existe material, [...] não tem vídeo, televisão. (Enfermeira, Nossa Senhora do Socorro, SE)

Um ponto consensual em todas as equipes analisadas é a compreensão de que as fragilidades de infraestrutura e diferentes limitações associadas com a organização da unidade ou do sistema local de saúde contribuem para a desumanização do trabalho e da atenção. A começar pela unidade de saúde, que, muitas vezes, configura-se como espaço produtor de doença:

A gente percebe até a própria condição do paciente a estrutura física influenciando. Muitos pacientes medem a PA com a auxiliar. Às vezes eu vou conferir a pressão e tá outra; eu pergunto: "É minha cara que tá fazendo isso?" E eles dizem: "Não, doutora, foi ter ficado aí na recepção num calor, uma zoada, uma confusão, entendeu? (Médica, Madre de Deus, BA)

Vale destacar, contudo, que encontramos duas situações contrastantes em relação à estru- tura física da unidade. Por um lado, registramos a satisfação por parte de alguns profissionais quanto ao seu tamanho e instalações (espaços apropriados para as consultas médicas, para a realização de atividades de promoção da saúde etc.); por outro, encontramos depoimentos enfáticos que faziam referência à precariedade desses mesmos itens. Os relatos positivos foram predominantes entre equipes das áreas urbanas dos municípios de grande porte. Entretanto, mesmo neste grupo foram observadas diferenças significativas entre os municípios. O maior índice de satisfação com as unidades de saúde foi registrado em Nossa Senhora do Socorro (SE), onde $63,6 \%$ dos profissionais consideraram as instalações adequadas ao trabalho. A situação é inversa em Vitória da Conquista (BA), onde as unidades foram apontadas como inadequadas por $57,1 \%$ dos entrevistados. Estas diferenças podem produzir situações peculiares na avaliação dos profissionais, além de servir de anteparo das disputas dos diversos projetos assistenciais ${ }^{17}$.

Acho que foi construído para ser um posto mesmo, lembra muito a questão do posto. Não tem um espaço pra fazer a educação em saúde, não tem espaço pra gente fazer nossa horta que a gente tanto tava planejando, [...] não suporto trabalhar ali, é um lugar muito barulhento. (ACS, Madre de Deus, BA)

O que se pode extrair de diferentes relatos é que um ambiente físico humanizado está associado a aspectos como tranquilidade, ventilação, proximidade com elementos da natureza. Assim, a unidade para trabalho da equipe deve ter "cara de PSF" e não "cara de posto ou de hospital":

O PSF, em minha opinião, deveria ser uma casa, com cara de aconchego, de acolher, varandas... (Auxiliar, Madre de Deus, BA)

No caso específico de Carmópolis (SE), os profissionais questionaram o fato de não terem sido consultados durante o processo de construção da USF na qual atuavam, resultando em uma unidade que não atende às necessidades da equipe. Os profissionais relatam a expectativa da equipe no decorrer da construção e a frustração após a finalização da obra:

Aí as meninas passavam e ansiosas diziam: "Já começou?" "Eu acho que vai ser de dois andares, porque embaixo vai ser a sala do médico, acho que em cima vai ter auditório." Aí começaram a colocar o telhado. (Enfermeira)

O espaço físico foi feito pra equipe, só que não chamaram ninguém da equipe para dizer o que precisava pra gente trabalhar no lugar [...] pior ainda: é uma só sala pro médico, colocou-se uma divisória, então ficou sendo ali sala da enfermeira, um cubículo. (Médico) 
E assim [...] a decepção dos agentes quando eles chegaram, que eles esperavam uma sala pra eles e não tinha. Eles continuam jogados, ficam na recepção, na farmácia. É difícil também você falar em humanização quando você não tem nem um espaçozinho confortável, né? (Auxiliar)

Queixas relacionadas especificamente à inadequação da farmácia foram registradas em unidades de Maracanaú (Ceará) e Vitória da Conquista (Bahia). A falta de medicamentos ou de outros insumos foi outro problema bastante referido pelos profissionais, de forma mais grave no caso dos programas especiais que limitam o cumprimento dos protocolos exigidos (como garantir quantidade exata de medicamentos ao programa de hipertensos) bem como nas atividades de prevenção.

A gente não dispõe de algumas medicações de atendimento primário, principalmente pra emergência antes de mandar pra unidade hospitalar. A gente tem problema também em relação ao material, principalmente quando se fala de prevenção, porque nosso material é dividido com outras unidades de saúde. (Enfermeira, Maracanaú, CE)

Hoje mesmo eu tô fazendo lâmina, então tem algumas pacientes que precisam de um creme vaginal e aí você prescreve e o paciente não tem dinheiro pra comprar e você não tem na unidade de saúde. (Enfermeira, Nossa Senhora do Socorro, SE)

No caso específico da odontologia, alguns dentistas destacam que a falta de material adequado dificulta a realização de procedimentos um pouco mais complexos ou compromete o resultado estético do tratamento realizado:
Às vezes a gente quer oferecer um tratamento mais sofisticado, só que as vezes você não tem como, não tem condições, entendeu? Quando eu falo sofisticado não é um implante. Eu falo de uma resina mais da cor do dente do paciente, porque às vezes a gente só tem uma cor, duas cores. Às vezes em criança fica totalmente diferente, entendeu? (Dentista, Nossa Senhora do Socorro, SE)

Outro obstáculo apontado pelas equipes na direção de uma atenção humanizada é a ausência de um sistema efetivo de referência e contrarreferência aos demais níveis de assistência nos municípios estudados. As Tabelas 1 e 2 descrevem a percepção dos profissionais com relação à retaguarda de especialidades médicas, laboratorial e hospitalar; nos municípios de grande porte prevaleceu a posição de parcialmente satisfatório em relação aos três itens avaliados, com exceção de Nossa Senhora do Socorro (SE), onde predominou a condição de insatisfatória para a retaguarda hospitalar. Entre os pequenos municípios, Madre de Deus (BA) apresentou os piores escores na avaliação do acesso a especialista e retaguarda hospitalar. O quadro mais favorável em ambos os itens foi registrado em Carmópolis. Em contrapartida, no tocante à retaguarda laboratorial, Madre de Deus revelou uma situação mais positiva que os demais municípios.

A ambulância e o suporte no encaminhamento dos pacientes são apontados como um fator importante no atendimento na unidade ou para viabilizar respostas esperadas no sistema local, como pode ser apreendido claramente nos depoimentos:

Tabela 1. Percepção dos profissionais sobre suporte clínico e laboratorial em USF em municípios de grande porte nos estados da Bahia, Ceará e Sergipe.

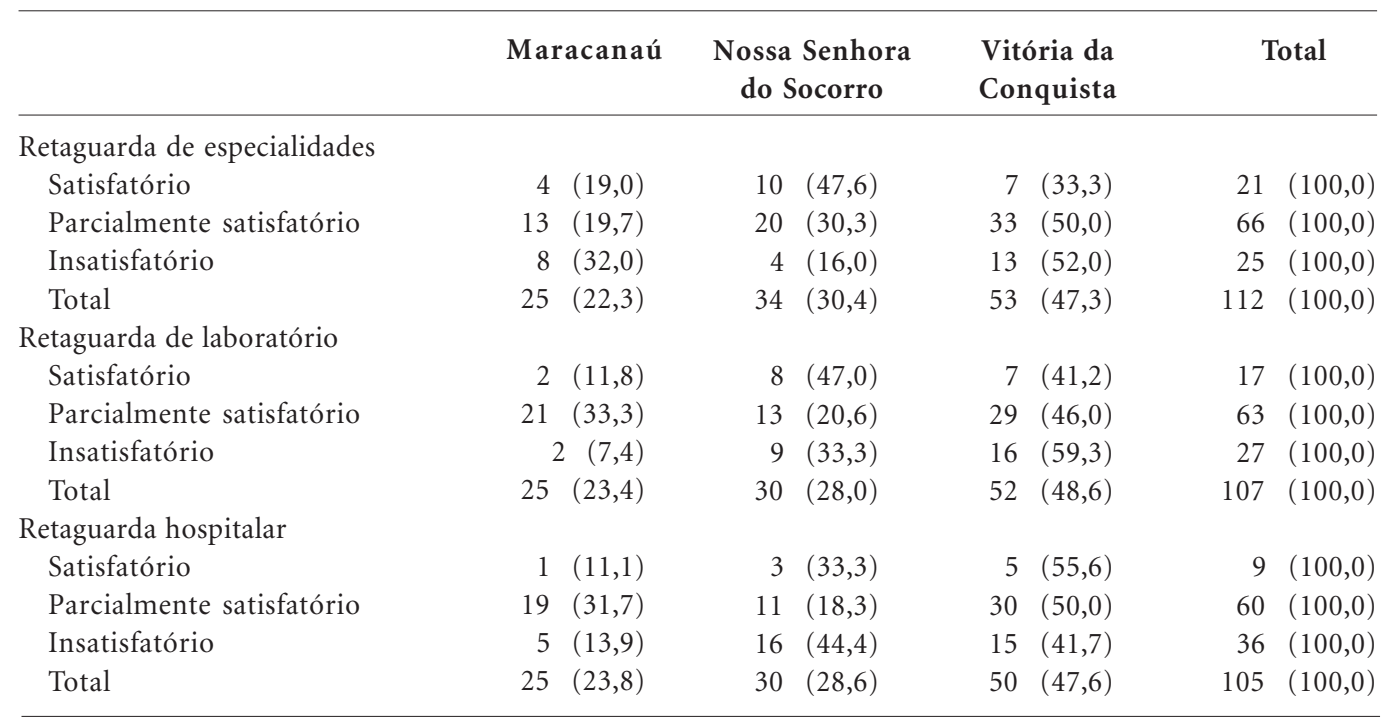




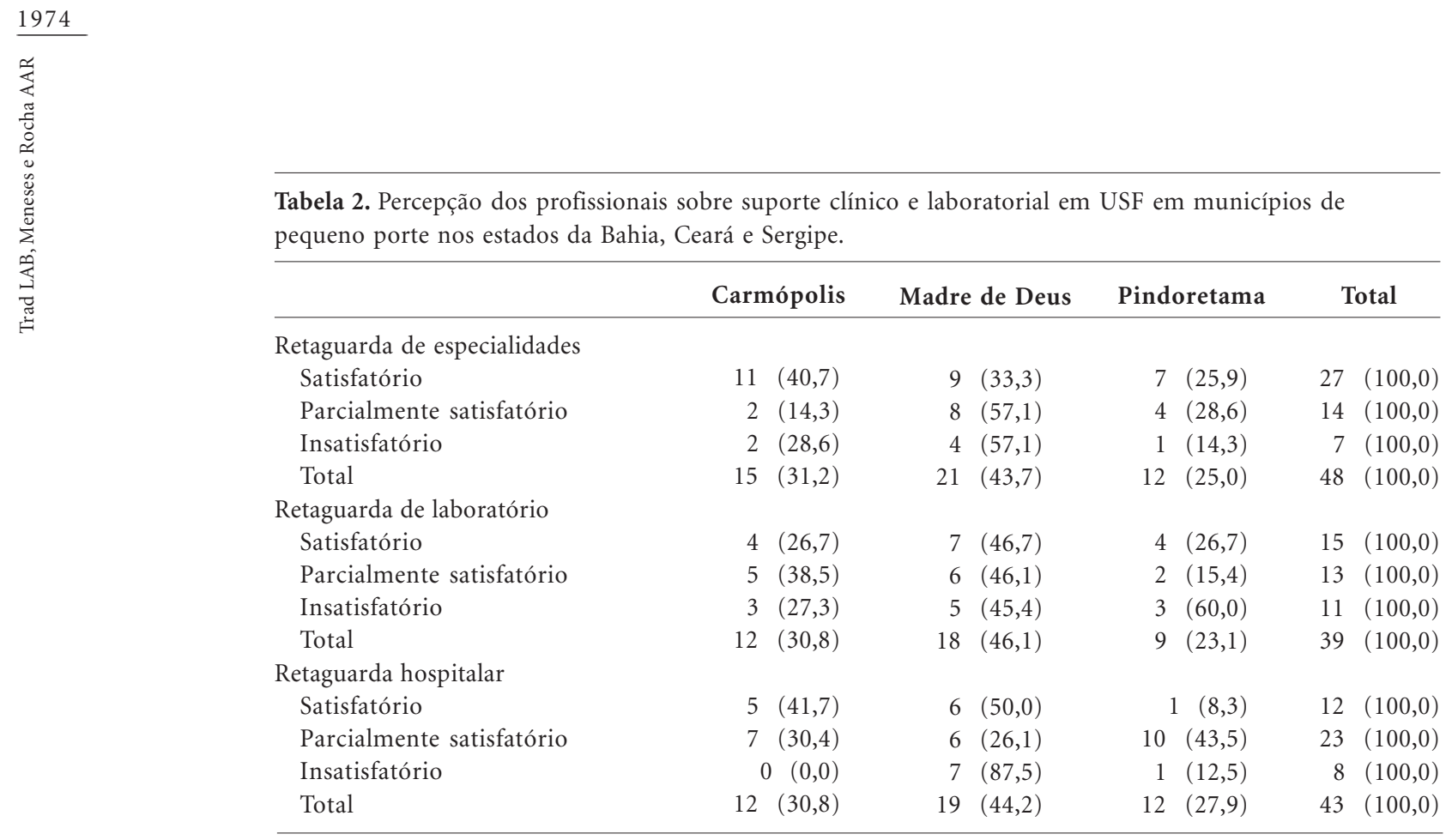

Como médica, é uma maravilha esta USF. Aqui do lado tem o Centro de Especialidades, atrás tem a central de ambulância, quer dizer, isso aqui é um complexo... Agora mesmo, antes de vir pra cá, tem um paciente cardiopata que não pode esperar, eu fui falar com a diretora, expliquei o caso [...] ambulância também é um privilégio. (Médica, Nossa Senhora do Socorro, SE)

Alguns profissionais identificam baixa integração do PSF com o sistema municipal de saúde e ressaltam a necessidade de os demais setores e secretarias municipais conhecerem a lógica do PSF para a consolidação do novo modelo de atenção preconizado. A falta de colaboração por parte de profissionais que atuam em outros níveis de atenção contribui para a "peregrinação" dos usuários e para sua insatisfação, tendo em vista as dificuldades de acesso. É um quadro que representa bem a chamada micropolítica das organizações de saúde ${ }^{18}$, caracterizada por uma realidade organizacional marcada por relações de poder, nas quais a rede tradicional com maior agregação tecnológica se coloca em um papel de superioridade ante a Atenção Primária:

É procurar entender realmente o sistema de saúde, entendeu? Pra que todos os setores pudessem saber o que éo PSF, porque nem todo mundo sabe, è̀s vezes dificulta [...] que não entendem, não falam a mesma língua. O outro ponto é a educação mesmo, é informação, é informar a comunidade, principalmente no hospital, porque a médica manda pra lá e aí eles não querem atender. O hospital diz: "Ah! Sua médica é muito preguiçosa, volte lá e procure seu
PSF." Então fica aquele jogo de empurra-empurra que atrapalha muito. (ACS, Madre de Deus, BA)

Como destacam Schimith e Lima ${ }^{10}$, existe uma diferença entre o projeto idealizado para o PSF e os resultados encontrados. As equipes têm dificuldades em resolver os problemas de acesso, observadas pela permanência nas filas para consultas, disputa na distribuição das fichas ou agenda médica lotada. A questão da sobrecarga de trabalho é um obstáculo a um trabalho humanizado, como mostra a Tabela 3, sendo mais contundente em Vitória da Conquista (BA) e em menor escala em Maracanaú (CE).

Nos municípios menores, encontramos certa uniformidade das opiniões, com discreta preponderância do município de Madre de Deus (BA) (Tabela 4). A sobrecarga de trabalho e de responsabilidades é uma queixa recorrente nas equipes do PSF $^{8,9,19-21}$

As causas da sobrecarga de trabalho são: o cadastramento ultrapassado subestimando o número de famílias da área, a pressão da demanda reprimida por consultas individuais e exames, o reduzido número de auxiliares para o trabalho administrativo, a deficiência estrutural da unidade, a pressão da SMS pela "produtividade" e o estabelecimento de cota de consultas diárias para os médicos. Estas duas últimas causas são referidas em Carmópolis e Nossa Senhora do Socorro (SE) com vistas à exigência do cumprimento das metas de Pactuação. A sobrecarga identificada impede, muitas vezes, a realização de atividades educativas e a consolidação de um 
Tabela 3. Percepção de sobrecarga de trabalho pelos profissionais das USF em municípios de grande porte nos estados da Bahia, Ceará e Sergipe.

\begin{tabular}{lrrrrr}
\hline & Maracanaú & Nossa Senhora do Socorro & Vitória da Conquista & Total \\
\hline $\begin{array}{l}\text { Carga de trabalho } \\
\text { Sempre }\end{array}$ & $7(14,6)$ & $9(18,7)$ & $32(66,7)$ & $48(100,0)$ \\
Frequentemente & $8(38,1)$ & $4(19,0)$ & $9(42,9)$ & $21(100,0)$ \\
Mais ou menos & $5(18,5)$ & $11(40,7)$ & $11(40,7)$ & $27(100,0)$ \\
Raramente & $4(28,6)$ & $8(57,1)$ & $2(14,3)$ & $14(100,0)$ \\
Nunca & $2(33,3)$ & $4(66,7)$ & $0(0,0)$ & $6(100,0)$ \\
Total & $26(22,4)$ & $36(31,0)$ & $54(46,5)$ & $116(100,0)$ \\
\hline
\end{tabular}

Tabela 4. Percepção de sobrecarga de trabalho pelos profissionais das USF em municípios de pequeno porte nos estados da Bahia, Ceará e Sergipe.

\begin{tabular}{lcccr}
\hline & Carmópolis & Madre de Deus & Pindoretama & Total \\
\hline Carga de trabalho & $7(33,3)$ & $7(33,3)$ & $7(33,3)$ & $21(100,0)$ \\
Sempre & $4(50,0)$ & $3(37,5)$ & $1(12,5)$ & $8(100,0)$ \\
Frequentemente & $4(25,0)$ & $10(62,5)$ & $2(12,5)$ & $16(100,0)$ \\
Mais ou menos & $2(50,0)$ & $1(25,0)$ & $1(25,0)$ & $4(100,0)$ \\
Raramente & $0(0,0)$ & $0(0,0)$ & $12(24,0)$ & $1(100,0)$ \\
Nunca & $17(34,0)$ & $21(42,0)$ & & $50(100,0)$ \\
Total & & &
\end{tabular}

modelo de atenção pautado na promoção da saúde ou de atividades implantadas mais recentemente (a exemplo da saúde bucal):

Tive pouca oportunidade de reunião de educação em saúde com a comunidade, mesmo porque há uma demanda reprimida para consulta individual; esta unidade tem cadastramento ultrapassado [...] é uma unidade que está com 1.400 familias, diferente do outro PSF, que estava com setecentas e poucas familias, onde havia mais frequente a educação em comunidade [...] nestes oito meses, foram duas as reuniões. (Médica, Madre de Deus, BA)

Aqui na unidade a gente tem que dar cobertura odontológica para três equipes, então é uma demanda muito grande. (Dentista, Maracanaú, CE)

Outro consenso entre as equipes do PSF refere-se à "experiência prévia dos profissionais" e aos "processos de formação/capacitação" em novas tecnologias requeridas no trabalho humanizado. Vitória da Conquista se destacou entre aqueles municípios que investem em estratégias de educação permanente, inclusive com ofertas de cursos sobre humanização do atendimento e saúde mental, entre outros. Os auxiliares e agentes referiram a participação frequente em atividades de treinamento e formação em saúde. Em contrapartida, foram registradas queixas quanto à defi- ciência dos processos de capacitação das equipes, com destaque para a ausência de treinamento da dentista e das auxiliares de enfermagem.

Lançaram elas sem treinamento, apesar de que elas conseguiram se sair bem observando como é que a coisa procede; é diferente auxiliar do plantão médico, da emergência, do que aquela que vai ficar lá no PSF. Elas conseguiram porque começaram a observar, a questionar. Mas em minha opinião faltou capacitação pra elas. (ACS, Madre de Deus, BA)

Elas [as ACS] fazem quatro anos e pouco que teve curso pra elas... Mas quando eu entrei eu não tive, ai quem foi me ensinando as coisas foram elas e agora que tem a enfermeira, né? Mas eu fui fazendo de acordo com que elas faziam, né? Então o meu curso foi com elas. (Auxiliar, Carmópolis, SE)

Em realidade, a falta de capacitação para o trabalho no PSF e na saúde coletiva como um todo foi um dado que emergiu no discurso da grande maioria dos profissionais investigados. No entanto, a maioria dos profissionais (tanto nos municípios de grande porte como nos de pequeno) demonstrou considerar-se competente ou mais ou menos competente para executar o trabalho no PSF (Tabela 5).

Não podemos esquecer de que as equipes do PSF são chamadas a prestar um cuidado integral 
à população adscrita, o qual inclui uma atenção clínica de tipo generalista e uma abordagem efetiva no eixo prevenção/promoção. Tal objetivo pode favorecer certa tensão entre os saberes e práticas dos profissionais e as exigências do programa e dos usuários ${ }^{8}$. Alguns depoimentos salientam que a formação recebida durante a graduação não prepara os profissionais para atuar na lógica do PSF, embora reconheçam avanços neste aspecto:

A bem da verdade [...] é que no fundo nós não somos preparados pela universidade para essa realidade. Agora até a universidade está mudando seu foco, então [...] é tudo difícil, isso para a gente chegar a esse nivel de relacionamento com os pacientes foi muito tempo. (Médico, Nossa Senhora do Socorro, SE)

As deficiências relatadas incluem em alguns casos a não realização do treinamento introdutório, considerada condição indispensável para iniciar o trabalho de qualquer equipe. Algumas queixas remetem aos critérios para inserção nos treinamentos oferecidos às equipes:

O que eu sinto falta é só com relação ao curso preparatório que já prometeram pra gente [...] $e$ não é só por mim, mas pelos meus colegas que também entraram e ainda não receberam nenhum curso. Eu tive uma base muito boa com relação ao PSF, sabe, na faculdade. Mas eu sinto dificuldade em muita coisa. (Médico, Maracanaú, CE)

$E$, a gente tá sempre sendo capacitado [...] mas médico, enfermeiro, odontólogo, pra eles tem mais capacitação. O auxiliar e os agentes ficam mais com a enfermeira, a enfermeira sempre faz isso com eles. (ACS, Nossa Senhora do Socorro, SE)

Nas áreas com déficits de saneamento básico, educação, moradia e transportes, que incidem diretamente na (má) qualidade de vida da população, há mais pressão sobre as equipes, em maior insatisfação quanto às condições de trabalho no PSF.

\section{Processo de trabalho da equipe}

A despeito das dificuldades apontadas no tópico anterior, o empenho em acolher as demandas e necessidades da população aparece como uma característica comum nas equipes estudadas, que, de modo geral, revelaram um alto grau de comprometimento com o trabalho que desenvolvem. Parece que a inserção no PSF favorece um tipo de engajamento que vai além do espaço e do horário de trabalho. A discussão de casos com outros colegas ou a programação de atividades educativas e sociais fora do horário regular de trabalho são alguns exemplos da dedicação das equipes. Em contrapartida, mudanças no processo de organização do trabalho e do serviço ainda são muito tênues. É patente, por exemplo, a dificuldade em superar a fragmentação do trabalho e construir uma prática interdisciplinar.

Ao explorar a percepção sobre as relações interpessoais, dinâmica do trabalho em equipe e definição de papéis e atribuições, os profissionais referiram ter uma boa convivência em equipe, classificando as relações entre eles como boas, cordiais, amigáveis; enfatizaram a importância do diálogo como via de superação dos momentos de conflitos e dificuldades no relacionamento. Os depoimentos apontam que a proximidade, a intimidade ou a confiança entre os profissionais estão associadas com o tempo de consolidação das equipes, sua estabilidade e o grau de articulação ou interdependência entre as atividades desenvolvidas na USF.

Tabela 5. Percepção dos profissionais sobre a competência da equipe para trabalhar em USF em municípios nos estados da Bahia, Ceará e Sergipe.

\begin{tabular}{|c|c|c|c|c|}
\hline & Carmópolis & Madre de Deus & Pindoretama & Total \\
\hline \multicolumn{5}{|c|}{ Competência da equipe } \\
\hline Incompetente & $0(0,0)$ & $1(100,0)$ & $0(0,0)$ & $1(100,0)$ \\
\hline Mais ou menos & $6(35,3)$ & $5(29,4)$ & $6(35,3)$ & $17(100,0)$ \\
\hline Competente & $11(34,4)$ & $15(46,9)$ & $6(18,7)$ & $32(100,0)$ \\
\hline \multirow[t]{2}{*}{ Total } & $17(34,0)$ & $21(42,0)$ & $12(24,0)$ & $50(100,0)$ \\
\hline & Maracanaú & Socorro & Vitória da Conquista & Total \\
\hline \multicolumn{5}{|c|}{ Competência da equipe } \\
\hline Incompetente & $1(100,0)$ & $0(0,0)$ & $0(0,0)$ & $1(100,0)$ \\
\hline Mais ou menos & $13(26,5)$ & $11(22,4)$ & $25(51,0)$ & $49(100,0)$ \\
\hline Competente & $13(19,7)$ & $24(36,4)$ & $29(43,9)$ & $66(100,0)$ \\
\hline Total & $27 \quad(23,3)$ & $35(30,2)$ & $54(46,5)$ & $116(100,0)$ \\
\hline
\end{tabular}


Eu acho que todo trabalho de equipe a gente tem que se engajar, correr atrás, saber o que o colega está fazendo. A médica está começando agora comigo, mas nós estamos nos entendendo muito bem, eu acredito que ela esteja vendo do mesmo jeito que eu. Não sei se é por causa do mesmo tipo de trabalho, a gente fica mais junto do médico, um complementa o trabalho do outro. (Enfermeira, Maracanaú, CE)

Acho que é o diálogo, porque sempre que tem qualquer problema entre a gente, sempre chama a outra e conversa. A gente confia muito na equipe. Uma coisa que ainda é muito boa no PSF III acho é a confiança entre nós mesmos. (ACS, Madre de Deus, BA)

Embora o trabalho em equipe tenha sido apontado de forma recorrente como um elemento bastante importante para a ruptura com o modelo assistencial tradicional, evidenciou-se que a concepção de um trabalho interdisciplinar, pautado na articulação entre os diferentes saberes e práticas, preconizado tanto pelo PSF como pela $\mathrm{PNH}$, constitui ainda um desafio para as equipes. Uma das grandes dificuldades observadas é a superação da fragmentação do trabalho. É preciso lembrar que o trabalho nos estabelecimentos de saúde, inclusive na atenção básica, foi tradicionalmente organizado de forma fragmenta$\mathrm{da}^{8}$, um processo claramente condicionado pela especialização do saber e pela atuação das corporações profissionais.

Chama a atenção a posição do odontólogo no PSF. A plena integração desse profissional na equipe do PSF aparece como um desafio a ser superado, na medida em que a saúde bucal coletiva surge como um modo (ideológico, operativo, contrahegemônico) de trazer a saúde bucal para o SUS. Os achados apontam para a dificuldade dos odontólogos em romper com modelos excludentes da atenção à saúde bucal que utiliza aspectos disciplinares estanques (como a epidemiologia, em seus levantamentos e análise da situação de saúde bucal da comunidade), com a manutenção das práticas (corporativas, centradas em queixas individuais, de baixo impacto epidemiológico), em prol de um novo modo de fazer saúde bucal como uma realidade a ser construída ${ }^{22-25}$.

Em alguns casos, esses aspectos ideológicos e conceituais se traduzem em um distanciamento físico e organizacional dos odontólogos das equipes (como em Carmópolis, SE), e os profissionais expressam claramente sua exclusão do cotidiano do trabalho da equipe e da comunidade.

Essa questão é muito importante com relação à odontologia, porque eu acho que está um pouco excluída, não por causa do dentista, porque eu ten- to mudar cada vez mais, mas o pessoal dificulta. Sempre nas campanhas de vacinação, de dengue, tentam deixar os dentistas de fora, ou então no posto que tem duas equipes só querem trazer um dentista. Eu acho que se tem duas equipes, a área é maior, então precisa de dois dentistas. (Dentista,Maracanaú, CE)

Muitos problemas observados remetem inexoravelmente à questão do poder e da "tensão estruturante" descrita por Bonet ${ }^{26}$. As demandas sociais que as equipes apresentam exigem uma nova prática que requer maior integração entre os profissionais, o que entra em choque com a formação dos profissionais, que privilegia a perspectiva biomédica em contraponto com a necessidade de privilegiar a intersubjetividade para melhor entendimento e resposta à comunidade. Em determinados momentos, a pretendida solidariedade e cooperação entre os membros da equipe cede lugar a disputas interprofissionais, configurando a realidade da nova prática pretendida que se encontra, simultaneamente, em crise e em construção ${ }^{27}$.

A organização dos papéis de cada profissão, no tocante ao receituário da enfermagem [...] que receitava os remédios dos programas. Aí o conselho de medicina caiu em cima [...] que só podia o médico e dentista prescrever e tal. Eu não digo ela consultar, mas existe a consulta médica, a consulta do dentista e a consulta de enfermagem, isto existe, né? (Médico,Maracanaú, CE)

O que eu vejo é que elas [auxiliares de enfermagem] estão sobrecarregadas, até a relação com a equipe é complicada. Elas não podem nem participar das reuniões de equipe que a gente faz semanalmente porque elas não podem sair lá da sala de curativo. (Dentista, Madre de Deus, BA)

As dificuldades observadas no entrosamento ou na divisão de tarefas entre profissionais de nível superior e nível médio refletem uma divisão de poder na equipe. A tomada de decisão é centrada nos profissionais de nível superior. É interessante também destacar o lugar ocupado pela enfermeira. A tarefa de gerenciar a unidade é considerada pela maioria como função primordial (ou exclusiva) desta profissional, reconhecida por muitos como "coordenadora da unidade", "responsável por marcar e conduzir as reuniões da equipe". Um fato que reflete o reconhecimento de uma suposta vocação administrativa dessa categoria profissional ${ }^{20,21}$. Porém, nem todos da equipe, incluindo as próprias enfermeiras, concordam com a ideia dessa concentração de tarefas e defendem a ideia de que a responsabilidade deveria ser compartilhada por todos os profissionais de nível superior da equipe: 
A responsabilidade de coordenar o PSF não deveria ser só de uma única pessoa, que no caso é a enfermeira. Isso deveria ser compartilhado com outros de nível superior. (ACS, Madre de Deus, BA)

A gente tenta dividir de melhor forma as tarefas, porque, infelizmente, apesar de ter a enfermeira e o médico, é muita gente. O volume de pacientes é razoável, mas a gente faz [...] até porque não é desorganizado [...] até porque nós temos o interesse e a boa vontade de atender a todos, está entendendo? Com cordialidade, confiança, solidariedade. (Auxiliar, Nossa Senhora do Socorro, SE)

No PSF, muita coisa fica pra o enfermeiro. Às vezes eu acho que quase todo o Programa, quase tudo fica nas costas do enfermeiro, e a responsabilidade é muito grande, a cobrança em cima de mim é muito grande. (Enfermeira, Carmópolis, SE)

O tema da hierarquia na equipe de saúde da família foi polemizado em alguns grupos focais. Em um deles, observamos a divergência de opinião entre os membros de uma equipe. A médica defende a necessidade de uma hierarquia técnica e de poder motivada pela diferença de conhecimento entre os diferentes profissionais, o que chama de "hierarquia técnica e de chefia", e é questionada por um dos agentes e pelo dentista da equipe.

[...] atribuições diferentes, direitos e deveres diferentes também. Existe o nível médio, superior, o nível técnico. Não tô falando de nível social, educacional, não, tô falando de conhecimento e responsabilidade. É necessário a hierarquização do serviço, sim, ela se faz necessária, ela é instalada a partir do núcleo da família. (Médica, Madre de Deus, BA)

É justamente com este modelo que eu não concordo. Numa equipe de PSF, cada um tem sua atribuição, não há necessidade de ninguém exercer poder sobre ninguém. Eu falo isso no PSF, porque é este sistema que a gente tá querendo implantar na comunidade. Todo mundo tem responsabilidade com a sua saúde, então não deveria existir aquela pessoa que fizesse papel de chefia, já que cada um conhece as suas atribuições [...] porque se só eu fizer minha função o programa não funciona, se a médica só fizer o dela não funciona, é por isso que é grupo, equipe. (ACS, Madre de Deus, BA)

Eu não entendo quando você fala chefia, que postura seria de uma chefe técnica [...] o que eu tô falando aqui é de poder, eu não enxergo esta hierarquia de poder, chefia. (Dentista, Madre de Deus, BA)

Em um contexto de atenção, no qual os profissionais não édicos passam a usar todo o seu arsenal tecnológico na escuta e na solução de problemas de saúde trazidos pela população usuária dos serviços, é esperada uma disputa pela supremacia do saber e do poder no serviço de saúde, até então um monopólio médico ${ }^{8,19}$.
Algumas unidades possuem a figura do gerente, cuja relação com a equipe é apresentada ora como conflitante, ora como pacífica. Um dos obstáculos a uma maior integração e articulação na equipe é a falta de clareza ou um entendimento impreciso das competências entre os trabalhos dos diferentes profissionais, que repercute negativamente no compartilhamento das ações, conforme o depoimento a seguir:

Aqui no município, infelizmente, a gente não tem ainda uma definição real de papéis. O PSF começou, já faz algum tempo, mas aqui a gente ainda vê [...] sei lá, um pouco de confusão. É uma ideia nossa agora, dos enfermeiros, a gente tem reuniões mensais, para tentar organizar as atividades de enfermagem. Eu sou uma que defende um protocolo do atendimento dos programas [...] é claro, o jeito de fazer é diferente, porque cada um aplica, naquele seu cuidado, um olhar diferente, um toque diferente, uma forma diferente de falar, $e$ isso é inerente de cada ser humano. (Enfermeira, Maracanaú, CE)

No que se refere às práticas desenvolvidas pelas equipes, são relatados vários entraves ao projeto de construção de um modelo de atenção orientado pela promoção da saúde. A quantidade de consultas exigida aparece como elemento restritivo à participação do médico nas ações educativas e na visita domiciliar, aliada à resistência explicada pela sensação de impotência em dar respostas à população, notadamente nas áreas mais pobres.

Quando o médico e a enfermeira chegam, não se preocupe que vêm dez atrás pedindo para ser atendido, e assim como você pode começar a mudar, a orientar? É que nós ficamos realmente presos à estrutura. A estrutura é a questão, atender trinta... atender trinta... (Médico, Nossa Senhora do Socorro, SE

Soma-se a isto a escassez de momentos coletivos de discussão que compromete a integração da equipe, a análise da situação de saúde do território e o planejamento das ações. Apesar do reconhecimento da importância estratégica da reunião semanal de equipe, tanto para favorecer o entrosamento e a cooperação entre os diferentes profissionais como para o planejamento e a avaliação das ações, a maioria das equipes referiu dificuldades na sua realização sistemática. Além da periodicidade irregular das reuniões de equipe, percebe-se que, em diferentes unidades, apenas a enfermeira e os agentes comunitários participam regularmente desse momento. Alguns depoimentos indicam, inclusive, uma perda progressiva no desenvolvimento dessa atividade na rotina do PSF:

$\mathrm{Na}$ administração anterior a gente se reunia todos uma vez no mês pra fazer uma programação 
das atividades. Sentava os profissionais pra discutir o que ia fazer no mês, qual era a programação, e infelizmente isso não está acontecendo. (ACS, Maracanaú, CE)

A gente sente falta hoje é das nossas reuniões. Antes era mensalmente [...] Nas reuniões debatia tudo... Depois que L saiu e a outra entrou raramente temos reuniões, é uma coisa que precisa mudar. Agora que somos concursados tivemos uma reunião, mas foi toda passada junto com o secretário, com a diretoria, mas não é isso que a gente está precisando. (Enfermeira, Nossa Senhora do Socorro, SE)

São ainda mais raros os encontros entre as equipes e as coordenações/gestão das SMS, um elemento considerado importante para o bom andamento das atividades de planejamento e gestão do PSF, além de ser uma demanda constante das equipes ${ }^{28}$. Isso traz à tona a dificuldade de institucionalização da Estratégia Saúde da Famí$\operatorname{lia}^{29}$. Entre as consequências desse problema destacam-se as dificuldades das equipes de saúde da família em responder às demandas do cidadão e fazer prevalecer o direito a saúde, notadamente em grandes centros urbanos ${ }^{30}$.

A relação entre eles é percebida como "tensa", mediada por "exigências e cobranças". Enquanto as equipes pressionam por melhores condições de trabalho, os gestores exigem mais produtividade. Reedita-se aqui a situação descrita por Vilasboas e Paim ${ }^{31}$, na qual o planejamento não se traduz no cotidiano das equipes, ficando restrito aos dirigentes municipais na forma de cálculo estratégico em formatos não estruturados.

Em suma, coincidindo com a realidade encontrada em outras pesquisas ${ }^{7,13,28}$, os momentos de avaliação e planejamento são reduzidos, centrados no cumprimento de metas e tarefas determinadas no nível central, fato que contribui para restringir a prática do PSF no âmbito das demandas imediatas dos usuários.

\section{Considerações finais}

O estudo evidencia que as deficiências relatadas no plano da infraestrutura repercutem negativamente em diferentes aspectos do processo de trabalho desenvolvido pelas equipes, comprometendo significativamente a qualidade dos serviços prestados. O distanciamento ou pouco entendimento do cotidiano do trabalho do PSF por parte do gestor local, bem como a incipiência de momentos coletivos de planejamento, integrando diferentes profissionais, contribuem para dificultar a articulação entre a gestão do trabalho e da atenção e a ruptura efetiva com o modelo assistencial tradicional tal como preconiza a $\mathrm{PNH}$.

$\mathrm{Na}$ análise comparada entre os municípios, observa-se que os de grande porte têm menos dificuldades que os pequenos na retaguarda assistencial e contam no geral com instalações mais adequadas às necessidades do PSF. Em contrapartida, as equipes dos pequenos municípios demonstraram maior entrosamento das equipes.

Constata-se, sobretudo, que o enfrentamento cotidiano com as carências das unidades de saúde da família influencia claramente na condição física e emocional dos trabalhadores e desestimula a adesão a um modelo pautado na integralidade, na promoção da saúde e no enfoque interdisciplinar de atuação. Este último aspecto é reflexo também de fragilidades apontadas nos processos de qualificação das equipes que não favorecem a tranversalidade de conhecimentos e experiências e maior aproximação com a realidade que se pretende transformar.

\section{Colaboradores}

LAB Trad coordenou o estudo e participou de todas as etapas da pesquisa, definiu o escopo do artigo e atuou como autora principal na sua redação; AAR Meneses e Rocha coordenou o trabalho de campo no estado de Sergipe, participou de todas as etapas da pesquisa e dividiu com a autora principal a redação do artigo.

\section{Agradecimentos}

Gostaríamos de agradecer o apoio recebido das secretarias estaduais de saúde da Bahia, do Sergipe e do Ceará, das secretarias municipais de saúde dos seis município pesquisados e da Universidade Estadual do Ceará, que indicou pesquisadores de campo para estudo local. 


\section{Referências}

1. Brasil. Ministério da Saúde. Política Nacional de Humanização; 2004. [acessado 2008 ago 5]. Disponível em: http://portal.saude.gov.br/saude

2. Teixeira RR. Humanização e Atenção Primária. Cien Saude Colet 2005; 10(3):585-597.

3. Deslandes SF. Análise do discurso oficial sobre a humanização da assistência hospitalar. Cien Saude Colet 2004; 9(1):7-14.

4. Lacaz FAC, Sato L. Humanização e qualidade do processo de trabalho em saúde. In: Deslandes SF, organizadora. Humanização dos cuidados em saúde: conceitos, dilemas e práticas. Rio de Janeiro: Editora Fiocruz; 2006. p. 109-139.

5. Luz MT. Fragilidade social e busca de cuidados na sociedade civil de hoje. In: Roseni P, Matos RA. Cuidado: as fronteiras da integralidade. São Paulo: Hucitec; 2004. p. 9-20.

6. Benevides R, Passos E. Humanização na saúde: réplica ao debate. Interface - Comunic, Saúde, Educ 2005; 9(17):389-406.

7. Trad LAB, Bastos ACS, Santana EM, Nunes MO. Estudo etnográfico da satisfação de usuários do Programa de Saúde da Família (PSF) na Bahia. Cien Saude Colet 2002; 7(3):581-589.

8. Rocha AARM, Trad LAB. A trajetória profissional de cinco médicos do Programa Saúde da Família: os desafios de construção de uma nova prática. Interface - Comunic, Saúde, Educ 2005; 9:303-316.

9. Benevides R, Passos E. Humanização na saúde: um novo modismo? Interface - Comunic, Saúde, Educ 2005; 9(17):389-406.

10. Schimith MD, Lima MADS. Acolhimento e vínculo em uma equipe do Programa de Saúde da Família. Cad Saude Publica 2004; 20(6):1487-1494.

11. Ayres JR. Cuidado e humanização das práticas de saúde. In: Deslandes SF. Humanização dos cuidados em saúde: conceitos, dilemas e práticas. Rio de Janeiro: Editora Fiocruz; 2006. p. 49-84.

12. Yin R. Estudo de caso. São Paulo: Bookman; 1994.

13. Trad LAB, Bastos ACS. O impacto sociocultural do Programa de Saúde da Família (PSF): uma proposta de avaliação. Cad Saude Publica 1998; 14(4):429-435.

14. Bardin L. Análise de conteúdo. Lisboa: Edições 70; 1977.

15. Santos SMR, Jesus MCP, Amaral AMM, Costa DMN, Arcanjo RA. A consulta de enfermagem no contexto da atenção básica de saúde, Juiz de Fora, Minas Gerais. Texto contexto - Enferm 2008; 17(1):124-130. [acessado 2009 fev 13]. Disponível em: http://www. scielo.br/scielo.php

16. Silveira DS, Santos IS, Costa JSD. Atenção pré-natal na rede básica: uma avaliação da estrutura e do processo. Cad Saude Publica 2001; 17(1):131-139.

17. Conill EM. Ensaio histórico-conceitual sobre a Atenção Primária à Saúde: desafios para a organização de serviços básicos e da Estratégia Saúde da Família em centros urbanos no Brasil. Cad Saude Publica 2008; 24(Supl.1):S7-S16.

18. Cecílio LCO. A micropolítica do hospital: um itinerário ético-político de intervenções e estudos [tese]. São Paulo: Universidade de São Paulo; 2007.
19. Nunes MO. O agente comunitário de saúde: conquistas e conflitos desse personagem híbrido e polifônico. Cad Saude Publica 2002; 18(6):1639-1646.

20. Silva IZQJ, Trad LAB. O trabalho em equipe no PSF: investigando a articulação técnica e a interação entre os profissionais. Interface - Comunic, Saúde, Educ 2005; 9(16):25-38.

21. Copque HLF, Trad LAB. Programa Saúde da Família: a experiência de implantação em dois municípios da Bahia. Revista de Epidemiologia e Serviços de Saúde 2005; 14:223-233.

22. Roncalli AG. Epidemiologia e saúde bucal coletiva: um caminhar compartilhado. Cien Saude Colet 2006; 11(1):105-114.

23. Santos AM, Assis MMA. Da fragmentação à integralidade: construindo e (des)construindo a prática de saúde bucal no Programa de Saúde da Família (PSF) de Alagoinhas, BA. Cien Saude Colet 2006; 11(1):53-61.

24. Figueiredo GO, Brito DTS, Botazzo C. Ideologia, fetiche e utopia na saúde: uma análise a partir da saúde bucal. Cien Saude Colet 2003; 8(3):753-763.

25. Chaves SCL, Silva LMV. As práticas profissionais no campo público de atenção à saúde bucal: o caso de dois municípios da Bahia. Cien Saude Colet 2007; 12(6):1697-1710.

26. Bonet O. Aconselhamento médico e diversidade cultural: a busca de um enfoque integral na prática da medicina de família. In: Pinheiro R, Mattos RA, organizadores. Construção da integralidade: cotidiano, saberes e práticas em saúde. Rio de Janeiro: Abrasco; 2003.

27. Romano VF. A busca de uma identidade para o médico de família. Physis 2008; 18(1):13-25. [acessado 2009 fev 13]. Disponível em: http://www.scielo. $\mathrm{br} / \mathrm{scielo} . \mathrm{php}$

28. Rocha AARM, Evangelista MJ. Fazer saúde com dignidade: a aposta da SES. In: Sousa MF, organizador. A real-idade do PSF: conversando com quem faz. Rio de Janeiro: Cebes; 2003.

29. Teixeira CF. Saúde da família, promoção e vigilância: construindo a integralidade da atenção à saúde no SUS. Revista Brasileira de Saúde da Família 2004; Edição Especial:10-23.

30. Gomes MCPA, Pinheiro R. Acolhimento e vínculo: prática de integralidade na gestão do cuidado em saúde em grandes centros urbanos. Interface - Comunic, Saúde, Educ 2005; 9(17):287-301.

31. Vilasboas ALQ, Paim JS. Municipal health policy planning and implementation. Cad Saude Publica 2008; 24(6):1239-1250.

Artigo apresentado em 14/09/2008

Aprovado em 03/02/2009

Versão final apresentada em 25/02/2009 